\begin{tabular}{|c|l|}
\hline Title & $\begin{array}{l}\text { Preferential oxidation of carbon monoxide in excess hydrogen over platinum catalysts supported on different-pore sized } \\
\text { mesoporous silica }\end{array}$ \\
\hline Author(s) & Huang, Shengjun; Hara, Kenji; Okubo, Y asuhiro; Y anagi, Masaaki; Nambu, Hironobu; Fukuoka, A tsushi \\
\hline Citation & $\begin{array}{c}\text { A pplied Catalysis A : General, 365(2), 268-273 } \\
\text { https://doi.org/10.1016/.apcata.2009.06.023 }\end{array}$ \\
\hline Issue Date & 2009-08-31 \\
\hline Doc URL & http://hdl.handle.net/2115/39398 \\
\hline Type & article (author version) \\
\hline File Information & ACA G365-2_p268-273.pdf \\
\hline
\end{tabular}

Instructions for use 


\title{
Preferential oxidation of carbon monoxide in excess hydrogen over platinum catalysts supported on different-pore-sized mesoporous silica
}

\author{
Shengjun Huang ${ }^{\mathrm{a}}$, Kenji Hara ${ }^{\mathrm{a}}$, Yasuhiro Okubo ${ }^{\mathrm{b}}$, Masaaki Yanagi ${ }^{\mathrm{b}}$, Hironobu \\ Nanbu ${ }^{b}$, Atsushi Fukuoka ${ }^{\mathrm{a}, *}$ \\ ${ }^{a}$ Catalysis Research Center, Hokkaido University, Kita-21 Nishi-10, Kita-ku, Sapporo \\ 001-0021, Japan \\ ${ }^{\mathrm{b}}$ Taiyo Kagaku Co., Ltd., 1-3 Takaramachi, Yokkaichi, Japan. \\ * Corresponding author. Tel.: +81-11-706-9140; Fax: +81-11-706-9139. \\ E-mail address: fukuoka@cat.hokudai.ac.jp (A. Fukuoka)
}

\begin{abstract}
s
Preferential oxidation (PROX) of carbon monoxide in excess hydrogen has been studied on low Pt loading (0.5-1 wt\%) catalysts supported on a series of FSM-type mesoporous silica materials. A support effect has been observed, in which the catalytic activities are closely related with the pore diameter of the support, despite their similar specific surface areas. Pt nanoparticles supported on mesoporous silica with $4.0 \mathrm{~nm}$ pore diameter possess the highest CO conversion over a wide range of reaction temperature, i.e. ca. $100 \% \mathrm{CO}$ conversion in 298-423 K. As a comparison, the Pt particles in small pore supports (1.8 $\mathrm{nm}$ ) exhibit poor performance under the same reaction conditions, which is barely comparable to the Pt catalysts on amorphous silica. The discrepancy in the mesoporous silica is proposed to be related with the different activities of surface silanols in various supports.
\end{abstract}

Keywords: Mesoporous silica, Pore size, PROX, Pt catalysts 


\section{Introduction}

Hydrogen-driven polymer electrolyte fuel cells (PEFCs) are recognized as one of the promising power sources for electric vehicles and residential cogeneration systems [1]. Currently, hydrogen produced from the reformation of hydrocarbon or alcohols contains $0.5-1$ vol\% CO after the water-gas shift (WGS) reaction [2,3]. Since Pt-based anodes are extremely susceptible to the poisoning by $\mathrm{CO}$ at the operation temperature $(\sim 353 \mathrm{~K})$ of PEFCs $[1,4,5]$, the process of $\mathrm{CO}$ elimination is necessary for the production of hydrogen fuel. For this purpose, preferential oxidation of $\mathrm{CO}$ (PROX) in excess $\mathrm{H}_{2}$ is performed to decrease the $\mathrm{CO}$ concentration to the ppm level. Supported metal catalysts of $\mathrm{Pt}, \mathrm{Ru}, \mathrm{Au}$ and bimetallic systems are extensively investigated due to their high catalytic performances. Despite the achievements in the mechanistic investigations [6-8], most of the reported catalysts do not match the requirements for the catalytic performance, or can be active only in the temperature range higher than the operation temperature of PEFCs $[9,10]$. As a result, an additional cooling process is needed before the introduction of $\mathrm{H}_{2}$ into PEFCs. Many attempts have been made to improve the catalytic activity at lower temperature. It was reported that $\mathrm{Pt}-\mathrm{Fe} /$ mordenite showed complete removal of $\mathrm{CO}$ over $373 \mathrm{~K}[11,12]$. Pt-Co/YSZ was also reported to give high $\mathrm{CO}$ conversion at 383-420 K [13]. Ru-Pt core-shell nanoparticles on alumina exhibited high CO conversion, but the catalytic reactions were tested at low $\mathrm{CO}$ concentration with excess $\mathrm{O}_{2}(\mathrm{CO} 0.1 \mathrm{vol} \%$, $\mathrm{O}_{2} / \mathrm{CO}$ ratio 5) [14]. As seen in these reports, high $\mathrm{CO}$ conversion has only been obtained at a temperature higher than $373 \mathrm{~K}$ or with an $\mathrm{O}_{2} / \mathrm{CO}$ ratio of 1 and above. Hence, there still remains a challenge of catalyst design for high activity and selectivity at the stoichiometric $\mathrm{O}_{2} / \mathrm{CO}$ ratio $(1 / 2)$ and at low temperatures below $373 \mathrm{~K}$. Previously, we reported that Pt nanoparticles on mesoporous silica FSM-16 (Pt $5 \mathrm{wt} \%$ ) display extremely high CO conversion and selectivity at 323-423 K [15], but lowering the Pt loading has also been a task for the future practical application of this catalyst system.

Since the promotional effect was observed on FSM-16 and MCM-41 [15], we are also interested in the phenomena over other mesoporous silica supports. Firstly, a series of FSM-type mesoporous silica materials, with similar specific surface areas but different pore diameters, have been studied in the PROX reaction. A distinct support effect on the 
activity can be observed. With low levels of $0.5-1 \mathrm{wt} \%$ loading, Pt/FSM-22 (4.0 nm pore diameter) catalyst exhibits ca. $100 \%$ activity in the wide range of $298-423 \mathrm{~K}$, and also $100 \%$ selectivity under the optimized conditions. In contrast, the Pt/FSM-10 (1.8 nm pore diameter) catalyst with the same Pt loading possesses poor catalytic performance, which is barely comparable to that of Pt species on amorphous silica. Such results further reveal the promotional effect of a suitable support (mesoporous silica with $4.0 \mathrm{~nm}$ pore) in lowering the Pt loading. The different support effect is proposed to be related with the different assembly and reactivity of surface silanols in mesoporous silica.

\section{Experimental}

Synthesis of FSM-type mesoporous silica: FSM-type mesoporous silicas with different pore diameters were synthesized according to the literature [16]. A calculated amount of kanemite was dissolved in the required amount of hot deionized water. The resultant solution was kept at $347 \mathrm{~K}$, and to this solution was added an alkyltrimethylalmmonium chloride $\left[\left(\mathrm{C}_{\mathrm{n}} \mathrm{H}_{2 \mathrm{n}+1}\right)\left(\mathrm{CH}_{3}\right)_{3} \mathrm{~N}\right] \mathrm{Cl}(\mathrm{n}=10,16$ or 22$)$. After stirring for $30 \mathrm{~min}$, the $\mathrm{pH}$ of the solution was adjusted to around 8.5 using an aqueous $36.5 \mathrm{wt} \% \mathrm{HCl}$ solution. The suspension was maintained at the aforementioned temperature for another $3 \mathrm{~h}$ with stirring. The product was recovered by filtration and repeatedly washed with deionized water. Finally the product was dried at $373 \mathrm{~K}$, followed by calcination in air at $823 \mathrm{~K}$ to remove the surfactant. The obtained silica was abbreviated as FSM- $n(x)$, where $n$ represents the carbon number in a long alkyl chain of surfactant and $x$ indicates the pore size in nanometers. For example, FSM-22(4.0) has $4.0 \mathrm{~nm}$ pore diameter, obtained from docosyltrimethylammonium chloride. For FSM-22(7.0), decane was incorporated as a swelling agent into the gels of silica source and $\left[\mathrm{C}_{22} \mathrm{H}_{45} \mathrm{~N}\left(\mathrm{CH}_{3}\right)_{3}\right] \mathrm{Cl}$ to enlarge the pore diameter [17]

Preparation of catalysts: The FSM-type mesoporous silicas and $\mathrm{SiO}_{2}$ (Fuji Silysia Cariact Q-10) were used as supports. Typically, $1.0 \mathrm{~g}$ support material was impregnated with $50 \mathrm{ml}$ aqueous solution containing $0.0269 \mathrm{~g} \mathrm{H}_{2} \mathrm{PtCl}_{6} 6 \mathrm{H}_{2} \mathrm{O}$ for $1 \mathrm{wt} \% \mathrm{Pt}$ loading $(0.0134 \mathrm{~g}$ in $50 \mathrm{ml}$ solution for $0.5 \mathrm{Pt} \mathrm{wt} \%)$. Each mixture was stirred for $18 \mathrm{~h}$, evaporated to dryness and dried under vacuum for $12 \mathrm{~h}$. The resulting solid was calcined 
in $\mathrm{O}_{2}$ flow at $473 \mathrm{~K}$ for $2 \mathrm{~h}$, and then reduced in $\mathrm{H}_{2}$ flow at $473 \mathrm{~K}$ for $2 \mathrm{~h}$. The Pt loading was $0.5-1 \mathrm{wt} \%$.

Characterization: $\mathrm{N}_{2}$ adsorption was carried out at $77 \mathrm{~K}$ with a Quantachrome Autosorb6 , and uptake of $\mathrm{CO}(323 \mathrm{~K})$ or $\mathrm{H}_{2}(298 \mathrm{~K})$ was measured with a Quantachrome Chembet-3000 in the pulse mode. Powder X-ray diffraction (XRD) patterns were recorded on a Rigaku Miniflex using $\mathrm{Cu} K \alpha$ radiation $(\lambda=0.15418 \mathrm{~nm})$ at $30 \mathrm{kV}$ and 15 $\mathrm{mV}$. Transmission electron microscopy (TEM) was performed with a JEOL JEM-2000ES at an accelerating voltage of $200 \mathrm{kV}$.

PROX reaction: Catalytic PROX reactions were conducted in a plug flow reactor (inner diameter $8 \mathrm{~mm}$ ) made of Pyrex . Mass flow of CO (99.9\%), $\mathrm{H}_{2}$ (99.999\%), $\mathrm{O}_{2}$ (99.999\%), $\mathrm{N}_{2}$ (99.999\%, internal standard), and $\mathrm{CO}_{2}(99.95 \%)$ were controlled by mass flow controllers. Powder of $0.5 \mathrm{wt} \% \mathrm{Pt} / \mathrm{FSM}-22(4.0)(0.4 \mathrm{~g})$ or $1 \mathrm{wt} \% \mathrm{Pt} / \mathrm{FSM}-n(x)(0.2 \mathrm{~g})$ was diluted with glass beads (diameter $1 \mathrm{~mm}, 4 \mathrm{~g}$ or $2 \mathrm{~g}$ ) and charged in the reactor. Each catalyst was reduced in $\mathrm{H}_{2}$ flow at $473 \mathrm{~K}$ for $90 \mathrm{~min}$, and then cooled to room temperature. The reactant gas mixture $\left(\mathrm{CO} 1 \mathrm{vol} \%, \mathrm{O}_{2} \quad 0.5-1\right.$ vol $\%, \mathrm{~N}_{2} 5$ vol\%, $\mathrm{H}_{2}$ balance with desirable flow rate) was fed to the reactor. Reactions with $\mathrm{CO}_{2}(15 \mathrm{vol} \%)$ and water vapor $(0.9$ or $2 \mathrm{vol} \%$, saturated at 278 or $293 \mathrm{~K})$ were also performed by adjusting the flow rate of $\mathrm{H}_{2}$. After reaching the steady state in ca. $1 \mathrm{~h}$, the outlet gas was analyzed by on-line gas chromatography for the separation of $\mathrm{H}_{2}, \mathrm{O}_{2}, \mathrm{~N}_{2}$ and $\mathrm{CO}$ using a Shimadzu GC 8A (thermal conductivity detector (TCD), a molecular sieve 13X (4 m) column, column temperature 323-453 $\left.\mathrm{K}\left(16 \mathrm{Kmin}^{-1}\right)\right)$ or using an Agilent Micro GC M200 (TCD, a molecular sieve 5A (10 m) + PopaPLOT U (3 m) column, column temperature $353 \mathrm{~K}$ ). The detection limit of $\mathrm{CO}$ was ca. $10 \mathrm{ppm}$ in our analysis. The $\mathrm{CO}$ conversion $\left(\chi_{\mathrm{CO}}\right)$ and the $\mathrm{CO}$ selectivity $\left(\mathrm{S}_{\mathrm{CO}}\right)$ are calculated as follows: $\chi_{\mathrm{CO}}=\left([\mathrm{CO}]_{\mathrm{in}}-\right.$ $\left.[\mathrm{CO}]_{\text {out }}\right) /[\mathrm{CO}]_{\text {in }} \times 100(\%), \mathrm{S}_{\mathrm{CO}}=(1 / 2)\left([\mathrm{CO}]_{\text {in }}-[\mathrm{CO}]_{\text {out }}\right) /\left(\left[\mathrm{O}_{2}\right]_{\text {in }}-\left[\mathrm{O}_{2}\right]_{\text {out }}\right) \times 100(\%)$, where $[\mathrm{CO}]$ or $\left[\mathrm{O}_{2}\right]$ is the concentration of $\mathrm{CO}$ or $\mathrm{O}_{2}$ in the flow gas.

\section{Results and Discussion}

\subsection{Characterization of catalysts}


The catalysts were characterized by physicochemical methods. The structural parameters are summarized in Table 1. Figure 1 shows XRD patterns of catalysts. Consistent with the reported studies on bare supports [16], the main (100) peak at the low $2 \theta$ angles shifts to lower diffraction angles from Pt/FSM-10(1.8) to Pt/FSM-22(4.0) as shown in Fig.1 (a) . In addition, the quality of the sample also increases with the length of the alkyl chain in surfactant, which is also accompanied by the presence of distinct (110) and (200) reflections. This corresponds to the variation of bare support and indicates that the mesoporous structure remains unchanged after the incorporation of Pt species. As shown in Fig. 2 (a), all samples exhibit a step on the isotherm. The position of the step shifts from $P / P_{0} \approx 0.1$ to $P / P_{0} \approx 0.5$ with the increasing surfactant chain length. For FSM22(4.0) and Pt/FSM-22(4.0), the capillary condensation occurs at $\mathrm{P} / \mathrm{P}_{0} \approx 0.5$ with almost vertical curves, indicating high homogeneity of the pore size and no plugging of the pore by Pt. Accordingly, the pore size distribution (Fig. 2 (b)) gives similar narrow peaks centered at $4.0 \mathrm{~nm}$ for FSM-22(4.0) and Pt/FSM-22(4.0). Despite the differences in XRD patterns and pore size distributions, the specific surface areas of these samples are quite close to each around at $\sim 1000 \mathrm{~m}^{2} / \mathrm{g}$. The above XRD and $\mathrm{N}_{2}$ adsorption characterization results in Table 1, Fig. 1 and Fig. 2 agree well with the reported results [16].

The diffraction peaks at $40^{\circ}$ and $46^{\circ}$ in Fig. 1 (b) are assigned to (111) and (220) reflections of fcc Pt crystalline by comparison with the JCPDS card (No.04-0802). However, the estimation of Pt particles size based on XRD patterns is not applicable because of the low signal-to-noise ratio of the peaks at such low Pt loading. Figure 3 shows typical TEM images for the supported Pt catalysts. Ordered channels of mesoporous support and highly dispersed Pt particles are observed for the $1 \mathrm{wt} \% \mathrm{Pt} / \mathrm{FSM}$ 16(2.7) and $1 \mathrm{wt} \% \mathrm{Pt} / \mathrm{FSM}-22(4.0)$. The mean diameter of the observed Pt particles is $3.5 \mathrm{~nm}$ for $1 \mathrm{wt} \% \mathrm{Pt} / \mathrm{FSM}-22(4.0)$, suggesting that the Pt particles are located inside the pore. If one assumes spherical particles with fec structure [18], the dispersion should be $32 \%$ for the $3.5 \mathrm{~nm}$ Pt particles, while the observed dispersion is $22-29 \%$ (Table 1). From these data, we estimate that $70-80 \%$ of the surface of Pt particles is exposed to the gas phase for this sample. This also suggests almost no plugging of the pores by the $\mathrm{Pt}$ particles. In the TEM images of $1 \mathrm{wt} \% \mathrm{Pt} / \mathrm{FSM}-10(1.8)$ and $1 \mathrm{wt} \% \mathrm{Pt} / \mathrm{FSM}-22(7.0), \mathrm{Pt}$ nanoparticles are observed with relatively broader size distributions. For $1 \mathrm{wt} \% \mathrm{Pt} / \mathrm{FSM}-$ 
22(7.0), about half of the observed Pt particles are around $3.5 \mathrm{~nm}$, while the rest of Pt particles are large ones around $5.0 \mathrm{~nm}$. In the case of $1 \mathrm{wt} \% \mathrm{Pt} / \mathrm{FSM}-10(1.8)$, dispersed $\mathrm{Pt}$ nanoparticles less than $2.0 \mathrm{~nm}$ are present, while particles as large as $3 \mathrm{~nm}$ also exist, which should be definitely located on the external surface of the support taking support pore size into consideration. It is not practical to draw the complete images about the size distribution and location of Pt nanoparticles over various catalysts due to such low $\mathrm{Pt}$ loading and heterogeneity of support surface. However, from Fig.3, we can conclude that the Pt particles size is not simply decided by the pore size or by the dimensions of the channels.

\subsection{Catalytic results}

Figure 4 shows the distinct support effect on the catalytic performances of $1 \mathrm{wt} \%$ Pt/FSM- $n(x)$. Under the excess $\mathrm{O}_{2}$ conditions $\left(\mathrm{O}_{2} / \mathrm{CO}=1\right)$, ca. $100 \% \mathrm{CO}$ conversion is achieved by $1 \mathrm{wt} \% \mathrm{Pt} / \mathrm{FSM}-22(4.0)$ at the operation temperature $(353 \mathrm{~K})$ of PEFCs. 1 wt\% Pt/FSM-16(2.7) with smaller pore diameter possesses a slightly lower CO conversion (96\%). However, the CO conversion decreases to $90 \%$ over catalyst with larger pore diameter of Pt/FSM-22(7.0) under the same conditions. The catalyst with the smallest pore diameter of Pt/FSM-10(1.8) gives ca. 40\% CO conversion at $353 \mathrm{~K}$. For the most active Pt/FSM-22(4.0), ca. 100\% CO conversion is achieved from $298 \mathrm{~K}$ to $423 \mathrm{~K}$. For less active $1 \mathrm{wt} \% \mathrm{Pt} / \mathrm{FSM}-16(2.7)$ and $1 \mathrm{wt} \% \mathrm{Pt} / \mathrm{FSM}-22(7.0)$, the majority of CO was removed at a temperature higher than $393 \mathrm{~K}$. As a comparison, $1 \mathrm{wt} \% \mathrm{Pt} / \mathrm{FSM}-$ 10(1.8) showed distinctly poor performance for the reaction, and only $70 \% \mathrm{CO}$ conversion at $423 \mathrm{~K}$, which behaves just like $1 \mathrm{wt} \% \mathrm{Pt} / \mathrm{SiO}_{2}$ (prepared from Cariact Q10). As shown in Fig. 4 (b), the $\mathrm{O}_{2}$ also consumed completely over $1 \mathrm{wt} \% \mathrm{Pt} / \mathrm{FSM}$ 22(4.0), demonstrating the presence of the side oxidation of $\mathrm{H}_{2}$ over such most active catalysts.

Due to the superior performance of FSM-22(4.0) and FSM-16(2.7) (Fig. 4), these two supports were studied with lower Pt loading of $0.5 \mathrm{wt} \%$ in this reaction. As shown in Fig. 5, the $\mathrm{CO}$ conversion is ca. $100 \%$ over $0.5 \mathrm{Pt} / \mathrm{FSM}-22(4.0)$ from $298 \mathrm{~K}$ to $423 \mathrm{~K}$ with the optimized space velocity of $3000 \mathrm{~mL} \mathrm{~g}^{-1} \mathrm{~h}^{-1}$. It should be noted that such catalytic 
performance is still superior to that of the $0.5 \mathrm{wt} \% \mathrm{Pt} / \mathrm{FSM}-16(2.7)$ counterpart under the same reaction conditions, reconfirming the very high promotional support effect of FSM22(4.0). The $0.5 \mathrm{wt} \% \mathrm{Pt} / \mathrm{FSM}-22(4.0)$ can become very selective under this optimized space velocity condition. As depicted in Fig. 6, the CO conversion is ca. 100\% at 298$353 \mathrm{~K}$ with stoichiometric $\mathrm{O}_{2} / \mathrm{CO}=1 / 2$, meaning that the selectivity for $\mathrm{CO}$ oxidation $\left(\mathrm{S}_{\mathrm{CO}}\right)$ is ca. $100 \%$. The superior catalytic performances of $0.5 \mathrm{wt} \% \mathrm{Pt} / \mathrm{FSM}-22(4.0)$ are also demonstrated under the simulated practical conditions with water vapor and $\mathrm{CO}_{2}$. The CO conversion is ca. $100 \%$ at $298-423 \mathrm{~K}$ over this catalyst (Fig. 7 (a)), and such high activity remains for $27 \mathrm{~h}$ at $353 \mathrm{~K}$ (Fig. 7 (b)). The catalytic results in Fig.5, Fig.6 and Fig.7 verify the most superior promotional effect of FSM-22(4.0) for the PROX reaction, and confirm that Pt/FSM-22(4.0) is among the most active and selective catalysts for PROX.

\subsection{Discussion}

In the preceding work, researchers have found that the typical mesoporous silica of FSM-16(2.7) exhibits a unique promotional effect for the PROX reaction [15]. The differences between usual amorphous silica and FSM-16(2.7) were revealed by isotopetracer characterizations, in which the oxygen atoms in surface silanols have been found to be incorporated to the $\mathrm{CO}_{2}$ product. This demonstrates the catalytic role of surface silanols in this oxidative reaction. In this work, the difference among the mesoporous silicas (FSM-type) is further observed. As shown in Fig. 4, with the same Pt loading and similar specific surface areas, distinctly different activities as the function of pore diameter can be observed. Especially for $1 \mathrm{wt} \% \mathrm{Pt} / \mathrm{FSM}-10(1.8)$, its activity is just close to $1 \mathrm{wt} \% \mathrm{Pt} / \mathrm{SiO}_{2}$, despite its high specific surface area and distinctly higher Pt particle dispersion. In contrast, the FSM-22(4.0) shows much higher promotional effect than the typical FSM-16(2.7). Results show that the numbers of surface silanols decrease with the larger pore on the FSM- $n$ series-type mesoporous silica $[19,20]$. From these results, we can conclude that such promotional effect is not a universal phenomenon for the mesoporous silica, and that the discrepancy in activity cannot be explained in term of difference in the number of surface silanols. 
The dependence of catalytic activity on pore size has been observed over MCM-41 for the acetalization of cyclohexanone with methanol, in which an assembly of surface silanols has been proposed to work as the most active groups for the reaction [21]. On the other hand, there are indications of a heterogeneous distribution of silanol groups on the surface of MCM-41 [22]. The pore size effect of Pt/FSM- $n(x)$ can be understood from the viewpoint of the state of surface silanols. The FSM- $n$ type mesoporous silica with narrower pores has a larger number of hydrogen-bonded SiOH groups [19,20]. Such hydrogen-bonded Si-OH groups can form the stable six-member rings [23], which may hinder the reaction between silanols and adsorbed CO. The poor activity of $1 \mathrm{wt} \%$ Pt/FSM-10(1.8) may suffer from such assemblies of surface silanols. For the most active $1 \mathrm{wt} \% \mathrm{Pt} / \mathrm{FSM}-22(4.0)$, the complete $\mathrm{CO}$ conversion was also accompanied with formation of $\mathrm{H}_{2} \mathrm{O}$ under high space velocity. This is quite different from catalytic performances on $5 \mathrm{wt} \%$ Pt/FSM-16 (2.7), which simutaneously exhibits ca. 100\% CO conversion and $\mathrm{O}_{2}$ selectivity from $313 \mathrm{~K}$. This suggest the potential different reaction routes for the reduction of $\mathrm{CO}$ with the involvment of $\mathrm{H}_{2} \mathrm{O}$ over FSM-22(4.0) with low $\mathrm{Pt}$ loading. The related mechanistic investigation is under way.

\section{Conclusions}

In summary, support effects of various FSM- $n$ mesoporous silica can be observed even with the same Pt loading and similar specific surface areas. Pt/FSM-22(4.0) catalysts can proceed the PROX reaction with distinctly superior catalytic performance, i.e. ca. $100 \%$ activity and $100 \%$ selectivity under certain conditions.As a sharp contrast, Pt over support with smaller pores gives lower activity; especially, Pt/FSM-10(1.8) is just comparable to $\mathrm{Pt}$ on amorphorous silica. These results are informative for the preparation of Pt catalysts with lower Pt loading for further practical applications. The support effect of mesoporous silica can be understood in terms of a pore size effect, which influences the assemblies of surface silanols and the interactions with $\mathrm{CO}$ adsorbed on Pt surface.

\section{Acknowledgement}


This work was supported by a Grant-in Aid for Scientific Research on Priority Areas (No.18065001, "Chemistry of Concerto Catalysis") from the Ministry of Education, Culture, Sports, Science and Technology, Japan and by a Grant-in Aid for Development of Energy Conservation Technology from the Ministry of Economy, Trade and Industry, Japan. We thank Mr. K. Sugawara for TEM measurement.

\section{Reference}

[1] R.J. Farrauto, Y. Liu, W. Ruettinger, O. Ilinich, L. Shore, T. Giroux, Catal. Rev. - Sci. Eng. 49 (2007) 141-196.

[2] T.V. Choudhary, D.W. Goodman, Catal. Today 77 (2002) 65-78.

[3] A.F. Ghenciu, Curr. Opin. Solid State Mater. Sci. 6 (2002) 389-399.

[4] R.A. Lemons, J. Power Sources 29 (1990) 251-264.

[5] H. Igarashi, T. Fujino, M. Watanabe, J. Electroanal. Chem. 391 (1995) 119-123.

[6] I. Rosso, C. Galletti, G. Saracco, E. Garrone, V. Specchia, Appl. Catal. B 48 (2004) 195-203.

[7] M.J. Kahlich, H.A. Gasteiger, R.J. Behm, J. Catal. 171(1997) 93-105.

[8] A. Manasilp, E. Gulari, Appl. Catal. B 37 (2002) 17-25.

[9] K.I. Tanaka, M. Shou, H. He, X.-Y. Shi, Catal. Lett. 110 (2006) 185-190.

[10] A. Siani, B. Captain, O.S. Alexeev, E. Stafyla, A.B. Hungria, P.A. Midgley, J.M. Thoma, R.D. Adams, M.D. Amiridis, Langmuir 22 (2006) 5160-5167.

[11] M. Kotobuki, A. Watanabe, H. Uchida, H. Yamashita, M. Watanabe, Appl. Catal. A 307 (2006) 275-283.

[12] N. Maeda, T. Matsushima, H. Uchida, H. Yamashita, M. Watanabe, Appl. Catal. A 341 (2008) 93-97.

[13] E.Y. Ko, E.D. Park, H.C. Lee, D. Lee, S. Kim, Angew. Chem. Int. Ed. 46 (2007) 734-737.

[14] S. Alayoglu, A.U. Nilekar, M. Mavrikakis, B. Eichhorn, Nat. Mater. 7 (2008) 333338.

[15] A. Fukuoka, J. Kimura, T. Oshio, Y. Sakamoto, M. Ichikawa, J. Am. Chem. Soc. 129 (2007) 10120-10125. 
[16] S. Inagaki, A. Koiwai, N. Suzuki, Y. Fukushima and K. Kuroda, Bull. Chem. Soc. Jpn. 69 (1996) 1449-1457.

[17] J.L. Blin, C. Otjacques, G. Herrier, B.-L. Su, Langmuir 16 (2000) 4229-4236.

[18] R.M. Rioux, H. Song, J.D. Hoefelmeyer, P. Yang, G. A. Somorjai, J. Phys. Chem. B 109 (2005) 2192-2202.

[19] M. Katoh, K. Sakamoto, M. Kamiyamane, T. Tomida, Phys. Chem. Chem. Phys. 2 (2000) 4471-4475.

[20] T. Ishikawa, M. Matsuda, A. Yasukawa, K. Kandori, S. Inagaki, T. Fukushima, S. Kondo, J. Chem. Soc., Faraday Trans. 92 (1996) 1985-1989.

[21] M. Iwamoto, Y. Tanaka, N. Sawamura, S. Namba, J. Am. Chem. Soc. 125 (2003) 13032-13033.

[22] A. Cauvel, D. Brunel, F.D. Renzo, Langmuir 13 (1997) 2773-2778.

[23] X.-S. Zhao, G.-Q. Lu, A.K. Whittaker, G.J. Millar, H.-Y. Zhu, J. Phys. Chem. B 101 (1997) 6525-6531. 
Fig. 1. The XRD patterns of $1 \mathrm{wt} \% \mathrm{Pt} / \mathrm{FSM}-n(x)$ catalysts at low $2 \theta$ angles (a) and at high $2 \theta$ angles(b).

Fig. 2. $\mathrm{N}_{2}$ adsorption isotherms (a) and pore size distribution curves of FSM- $n(x)$ supports and $1 \mathrm{wt} \% \mathrm{Pt} / \mathrm{FSM}-n(x)$ catalysts (b).

Fig. 3. The TEM images of $1 \mathrm{wt} \%$ Pt/FSM- $n(x)$ catalysts. (a) $1 \mathrm{wt} \%$ Pt/FSM-16(2.7); (b) $1 \mathrm{wt} \%$ Pt/FSM-22(4.0); (c) 1 wt\% Pt/FSM-22(7.0); (d) 1wt\% Pt/ FSM-10(1.8).

Fig. 4. PROX reaction by $1 \mathrm{wt} \% \mathrm{Pt} / \mathrm{FSM}-n(x)$ under the excess $\mathrm{O}_{2} / \mathrm{CO}$ ratio of 1 . (a) CO conversion; (b) $\mathrm{O}_{2}$ conversion. (m: 1 wt $\%$ Pt/FSM-10(1.8), ०: 1 wt\% Pt/FSM-16(2.7), $1 \mathrm{wt} \% \mathrm{Pt} / \mathrm{FSM}-22(4.0), \Delta: 1 \mathrm{wt} \% \mathrm{Pt} / \mathrm{FSM}-22(7.0)$, - - --- - -: $1 \mathrm{wt} \% \mathrm{Pt} / \mathrm{SiO}_{2}$ ). Conditions: catalyst $0.2 \mathrm{~g}, \mathrm{CO} 1 \mathrm{vol} \%, \mathrm{O}_{2} 1 \mathrm{vol} \%, \mathrm{~N}_{2} 5$ vol $\%, \mathrm{H}_{2}$ balance, space velocity $12000 \mathrm{mLg}^{-}$ ${ }^{1} \mathrm{~h}^{-1}, 0.1 \mathrm{MPa}$.

Fig. 5. Catalytic performance of $0.5 \mathrm{wt} \% \mathrm{Pt} / \mathrm{FSM}-22(4.0)$ and $0.5 \mathrm{wt} \% \mathrm{Pt} / \mathrm{FSM}-16(2.7)$. (a) CO conversion; (b) $\mathrm{O}_{2}$ conversion. (- $\boldsymbol{\Delta}-: 0.5 \mathrm{wt} \% \mathrm{Pt} / \mathrm{FSM}-22(4.0) ;-\Delta-: 0.5 \mathrm{wt} \%$ Pt/FSM-16(2.7)). Conditions: catalyst $0.4 \mathrm{~g}$, CO 1 vol $\%, \mathrm{O}_{2} 1$ vol $\%, \mathrm{~N}_{2} 5$ vol $\%, \mathrm{H}_{2}$ balance, space velocity $3000 \mathrm{~mL} \mathrm{~g}^{-1} \mathrm{~h}^{-1}, 0.1 \mathrm{MPa}$.

Fig. 6. $\mathrm{PROX}$ reaction by $0.5 \mathrm{wt} \% \mathrm{Pt} / \mathrm{FSM}-22(4.0)$ under the stoichiometric $\mathrm{O}_{2} / \mathrm{CO}$ ratio of $1 / 2$. Reaction conditions: catalyst $0.4 \mathrm{~g}$, CO 1 vol $\%, \mathrm{O}_{2} 0.5 \mathrm{vol} \%, \mathrm{~N}_{2} 5 \mathrm{vol} \%, \mathrm{H}_{2}$ balance, space velocity $3000 \mathrm{mLg}^{-1} \mathrm{~h}^{-1}, 0.1 \mathrm{MPa}$.

Fig. 7. PROX reaction by $0.5 \mathrm{wt} \% \mathrm{Pt} / \mathrm{FSM}-22(4.0)$ in the presence of water vapor and $\mathrm{CO}_{2}$. (a) Reaction conditions: catalyst $0.4 \mathrm{~g}, \mathrm{CO} 1 \mathrm{vol} \%, \mathrm{O}_{2} 1$ vol\%, $\mathrm{N}_{2} 5$ vol\%, $\mathrm{CO}_{2} 15$ vol $\%, \mathrm{H}_{2} \mathrm{O} 0.9$ vol\%, $\mathrm{H}_{2}$ balance, space velocity $3000 \mathrm{~mL} \mathrm{~g}^{-1} \mathrm{~h}^{-1}, 0.1 \mathrm{MPa}$; (b) Reaction conditions: catalyst $0.4 \mathrm{~g}, \mathrm{CO} 1$ vol $\%, \mathrm{O}_{2} 1$ vol $\%, \mathrm{~N}_{2} 5$ vol $\%, \mathrm{CO}_{2} 15$ vol\%, $\mathrm{H}_{2} \mathrm{O} 2$ vol $\%$, $\mathrm{H}_{2}$ balance, space velocity $3000 \mathrm{mLg}^{-1} \mathrm{~h}^{-1}, 0.1 \mathrm{MPa}$. 
(a)

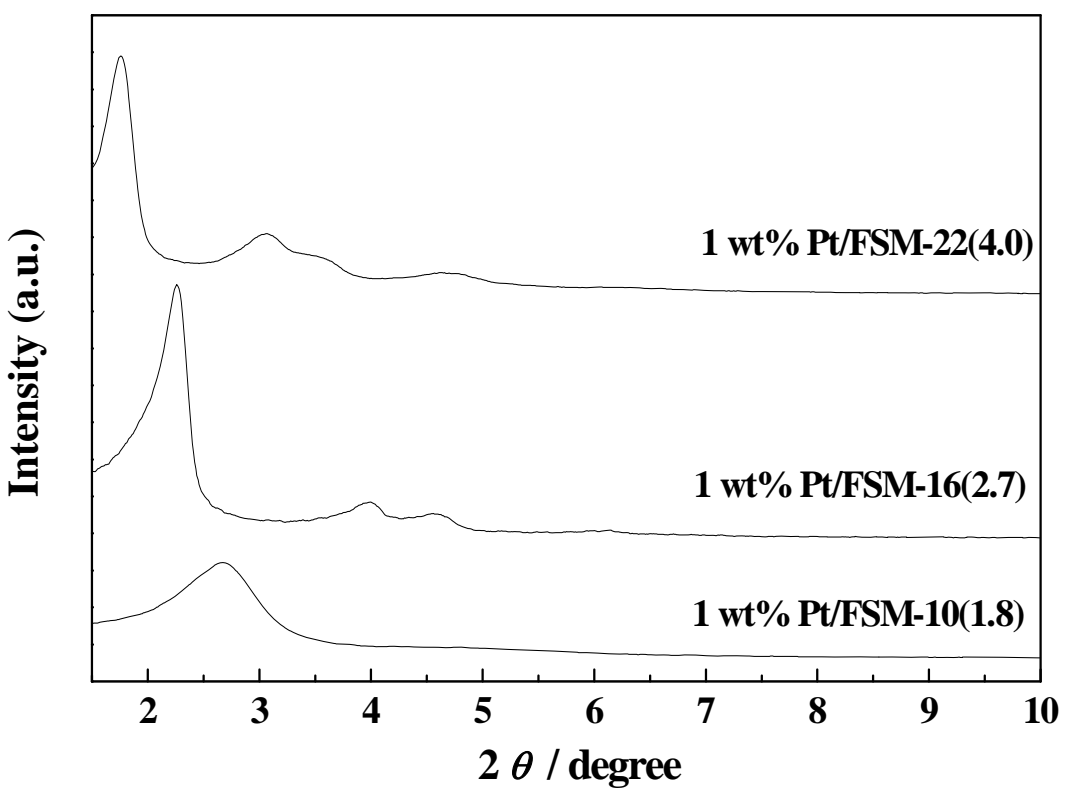

(b)

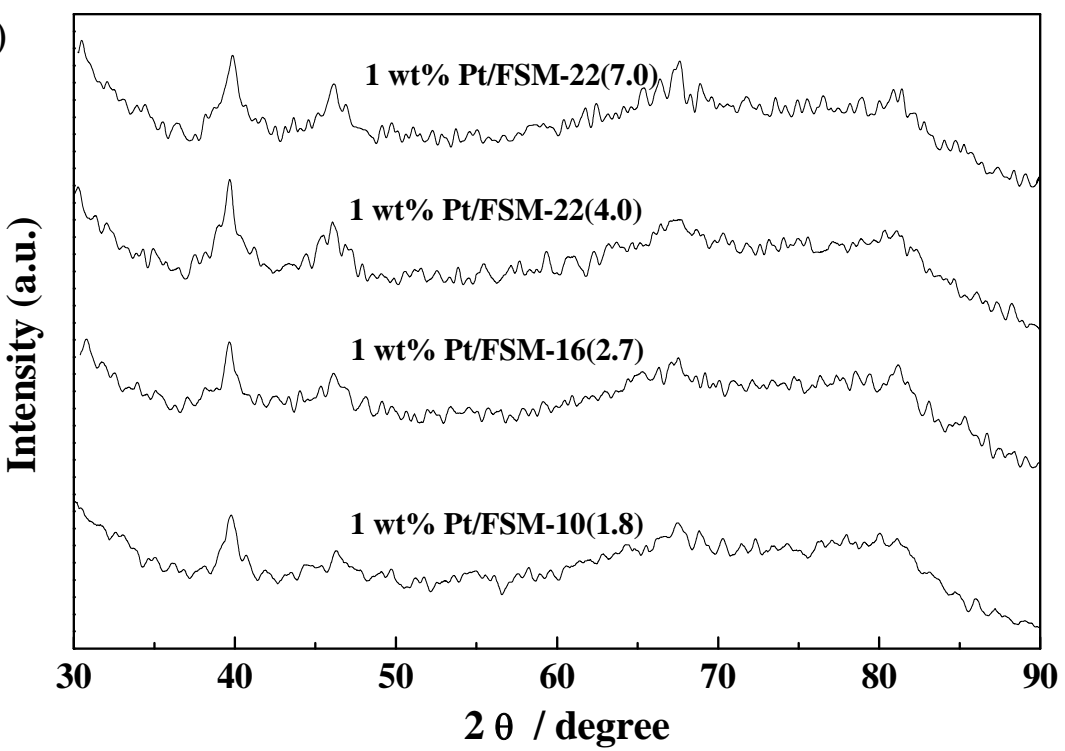

Fig. 1. The XRD patterns of $1 \mathrm{wt} \% \mathrm{Pt} / \mathrm{FSM}-n(x)$ catalysts at low $2 \theta$ angles (a) and at high $2 \theta$ angles (b). 
(a)

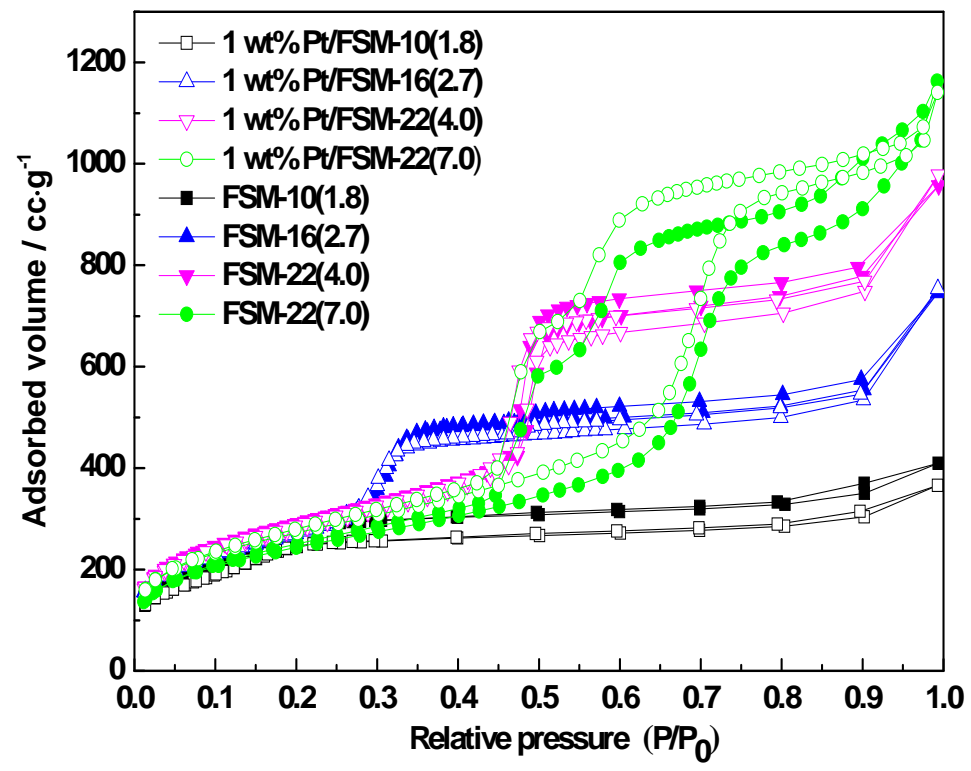

(b)

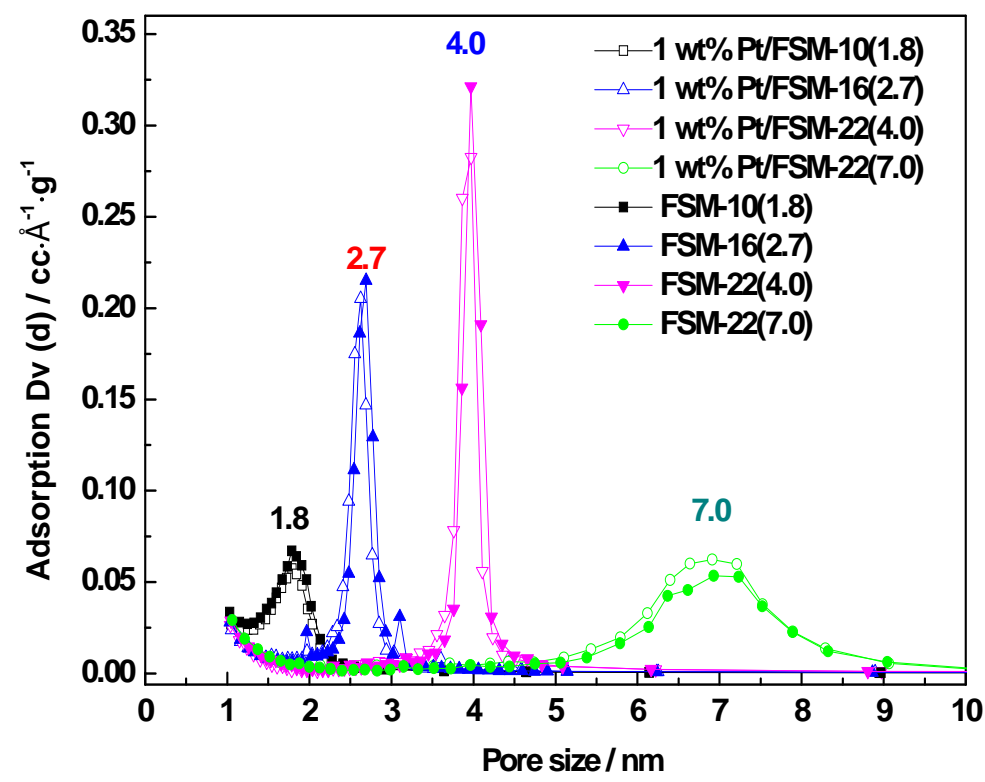

Fig. 2. $\mathrm{N}_{2}$ adsorption isotherms (a) and pore size distribution curves of FSM- $n(x)$ supports and $1 \mathrm{wt} \% \mathrm{Pt} / \mathrm{FSM}-n(x)$ catalysts (b). 
(a)

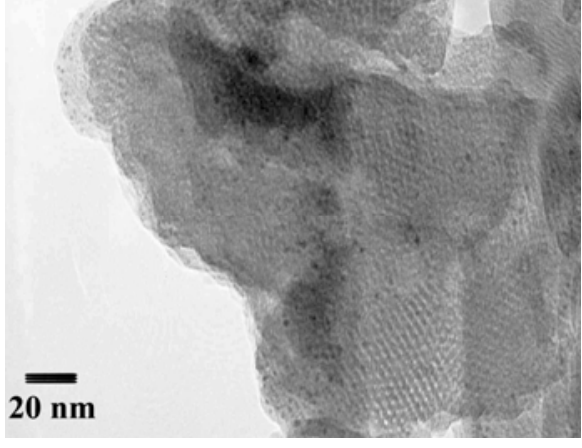

(c)

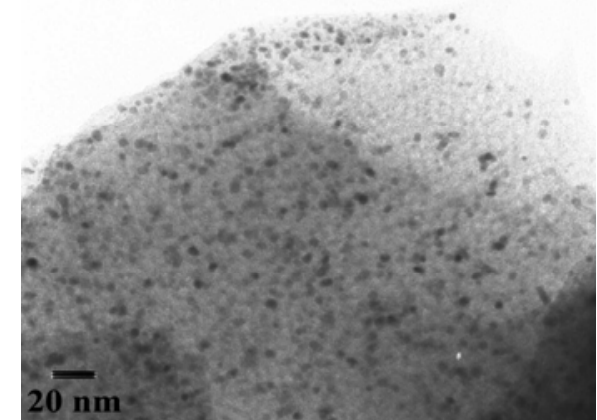

(b)

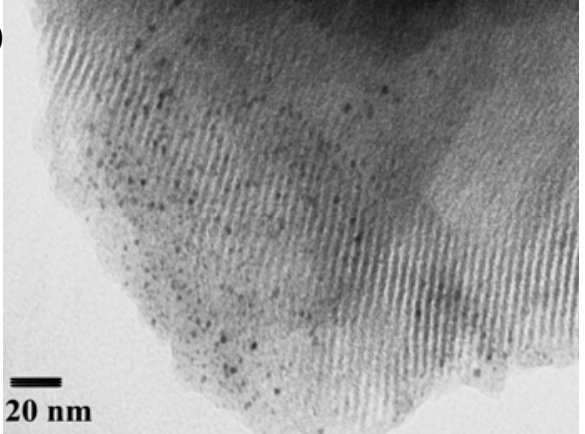

(d)

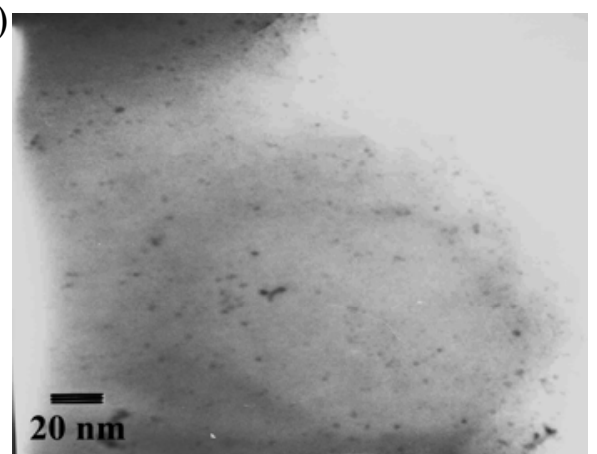

Fig. 3. The TEM images of $1 \mathrm{wt} \% \mathrm{Pt} / \mathrm{FSM}-n(x)$ catalysts. (a) $1 \mathrm{wt} \% \mathrm{Pt} / \mathrm{FSM}-16(2.7)$; (b) $1 \mathrm{wt} \%$ Pt/FSM-22(4.0); (c) $1 \mathrm{wt} \%$ Pt/FSM-22(7.0); (d) 1wt\% Pt/ FSM-10(1.8). 
(a)

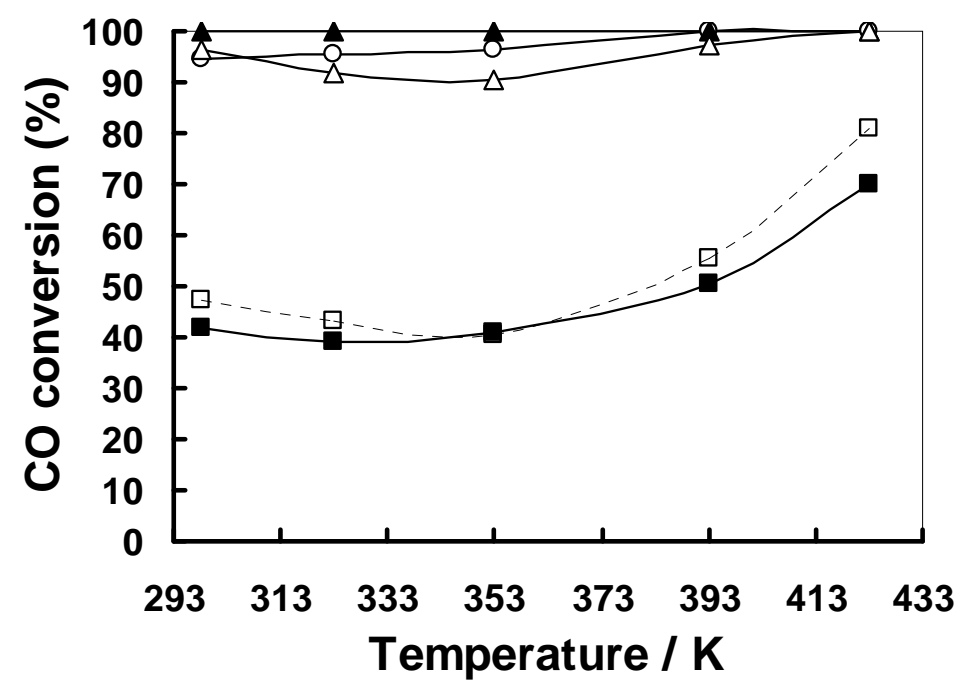

(b)

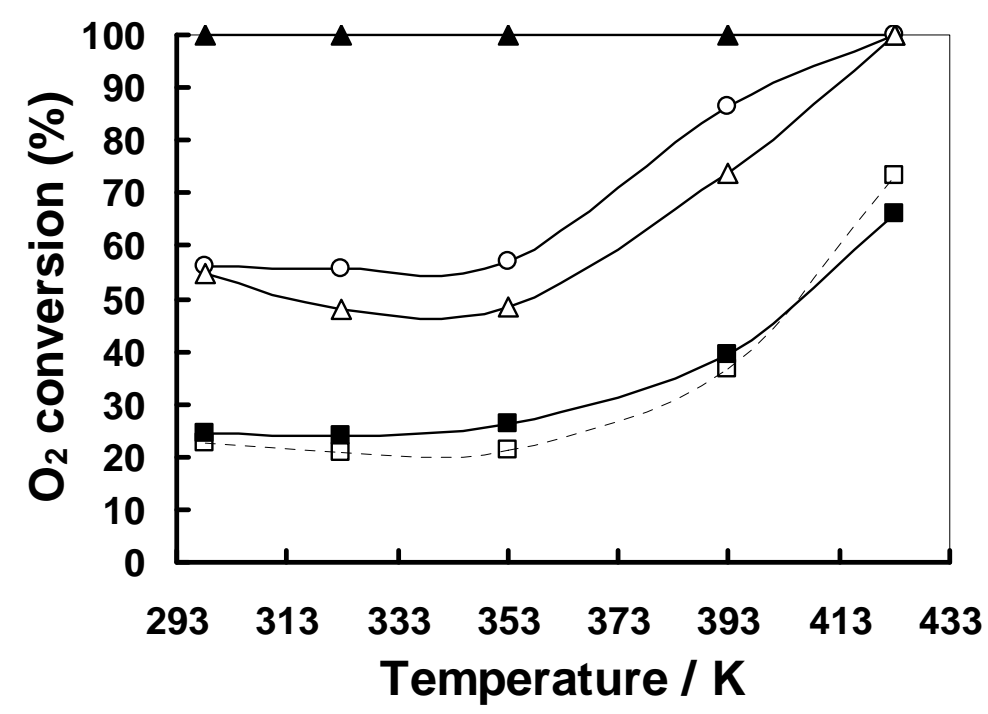

Fig. 4. PROX reaction by $1 \mathrm{wt} \% \mathrm{Pt} / \mathrm{FSM}-n(x)$ under the excess $\mathrm{O}_{2} / \mathrm{CO}$ ratio of 1 . (a) $\mathrm{CO}$ conversion; (b) $\mathrm{O}_{2}$ conversion. (a: $1 \mathrm{wt} \%$ Pt/FSM-10(1.8), ०: $1 \mathrm{wt} \%$ Pt/FSM-16(2.7), $1 \mathrm{wt} \% \mathrm{Pt} / \mathrm{FSM}-22(4.0), \Delta: 1 \mathrm{wt} \% \mathrm{Pt} / \mathrm{FSM}-22(7.0),-$ - - -- - -: $1 \mathrm{wt} \% \mathrm{Pt} / \mathrm{SiO}_{2}$ ). Conditions: catalyst $0.2 \mathrm{~g}, \mathrm{CO} 1 \mathrm{vol} \%, \mathrm{O}_{2} 1 \mathrm{vol} \%, \mathrm{~N}_{2} 5 \mathrm{vol} \%, \mathrm{H}_{2}$ balance, space velocity $12000 \mathrm{mLg}^{-}$ ${ }^{1} \mathrm{~h}^{-1}, 0.1 \mathrm{MPa}$. 
(a)

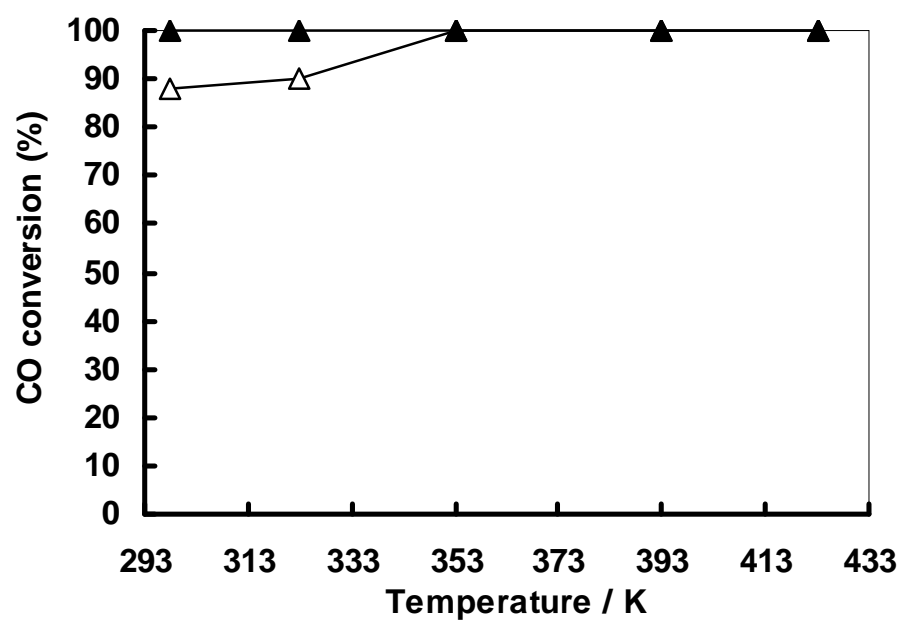

(b)

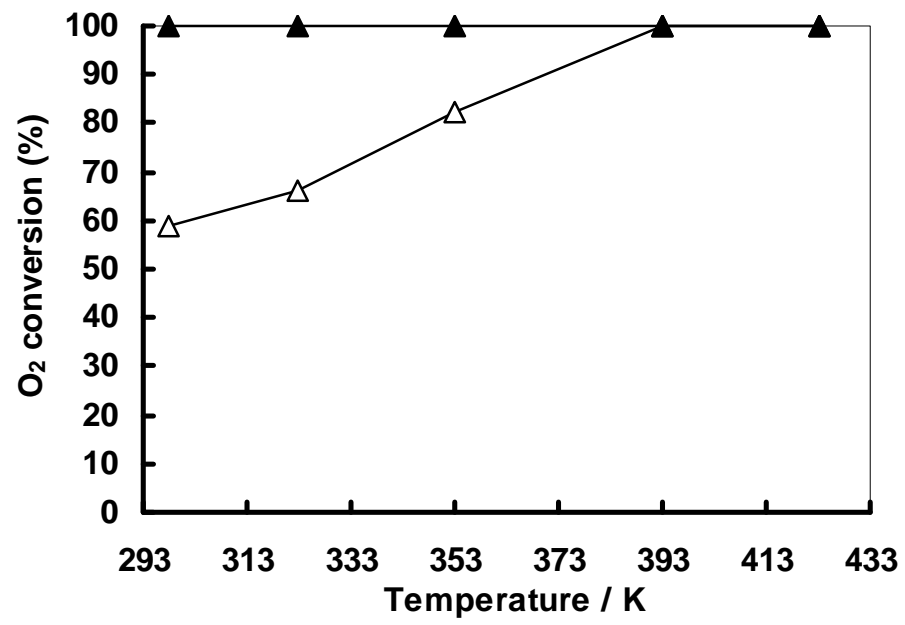

Fig. 5. Catalytic performance of $0.5 \mathrm{wt} \% \mathrm{Pt} / \mathrm{FSM}-22(4.0)$ and $0.5 \mathrm{wt} \% \mathrm{Pt} / \mathrm{FSM}-16(2.7)$. (a) $\mathrm{CO}$ conversion; (b) $\mathrm{O}_{2}$ conversion. (- $\Delta$-: $0.5 \mathrm{wt} \% \mathrm{Pt} / \mathrm{FSM}-22(4.0) ;-\Delta-: 0.5 \mathrm{wt} \%$ Pt/FSM-16(2.7)). Conditions: catalyst 0.4 g, CO 1 vol $\%, \mathrm{O}_{2} 1$ vol $\%, \mathrm{~N}_{2} 5$ vol $\%, \mathrm{H}_{2}$ balance, space velocity $3000 \mathrm{~mL} \mathrm{~g}^{-1} \mathrm{~h}^{-1}, 0.1 \mathrm{MPa}$. 


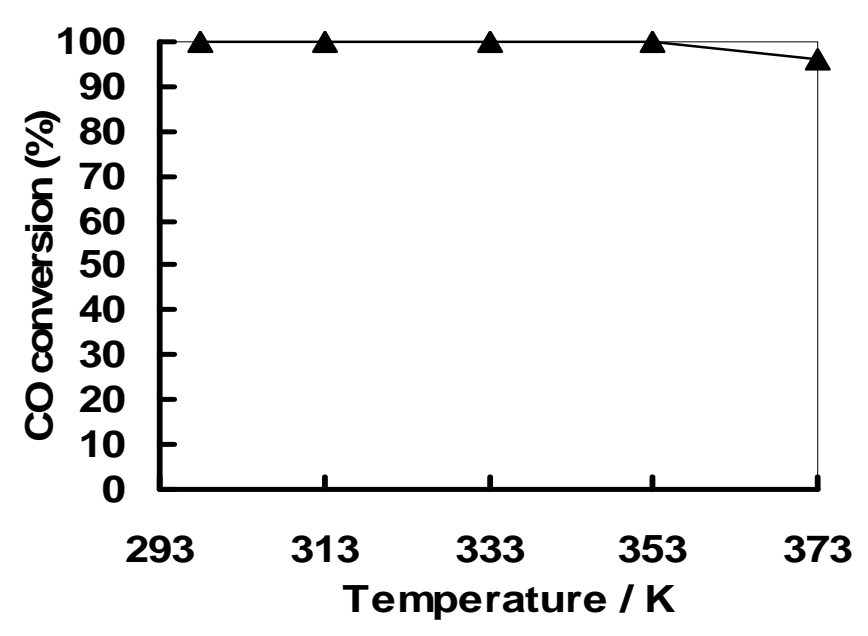

Fig. 6. $\mathrm{PROX}$ reaction by $0.5 \mathrm{wt} \% \mathrm{Pt} / \mathrm{FSM}-22(4.0)$ under the stoichiometric $\mathrm{O}_{2} / \mathrm{CO}$ ratio of $1 / 2$. Reaction conditions: catalyst $0.4 \mathrm{~g}, \mathrm{CO} 1 \mathrm{vol} \%, \mathrm{O}_{2} 0.5$ vol $\%, \mathrm{~N}_{2} 5 \mathrm{vol} \%, \mathrm{H}_{2}$ balance, space velocity $3000 \mathrm{mLg}^{-1} \mathrm{~h}^{-1}, 0.1 \mathrm{MPa}$. 
(a)

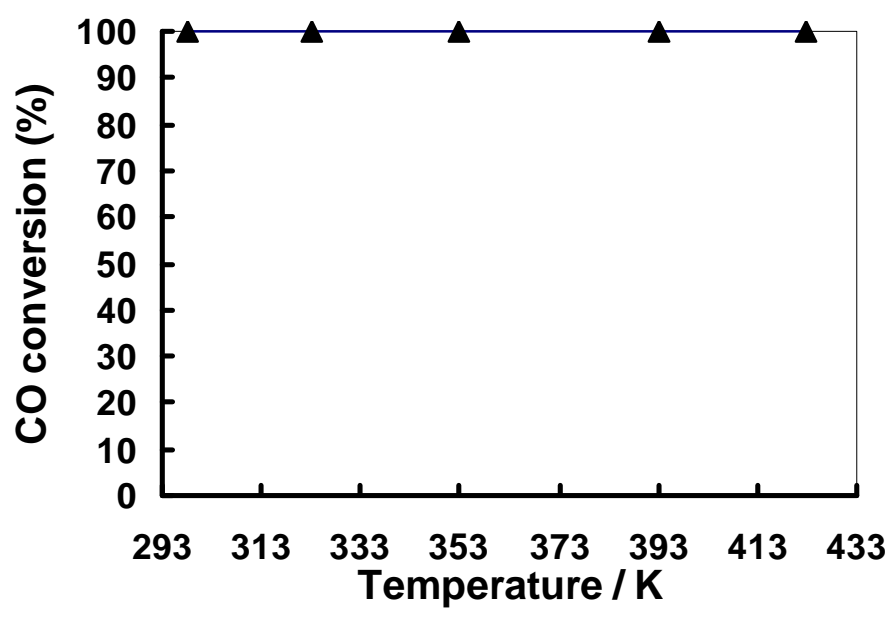

(b)

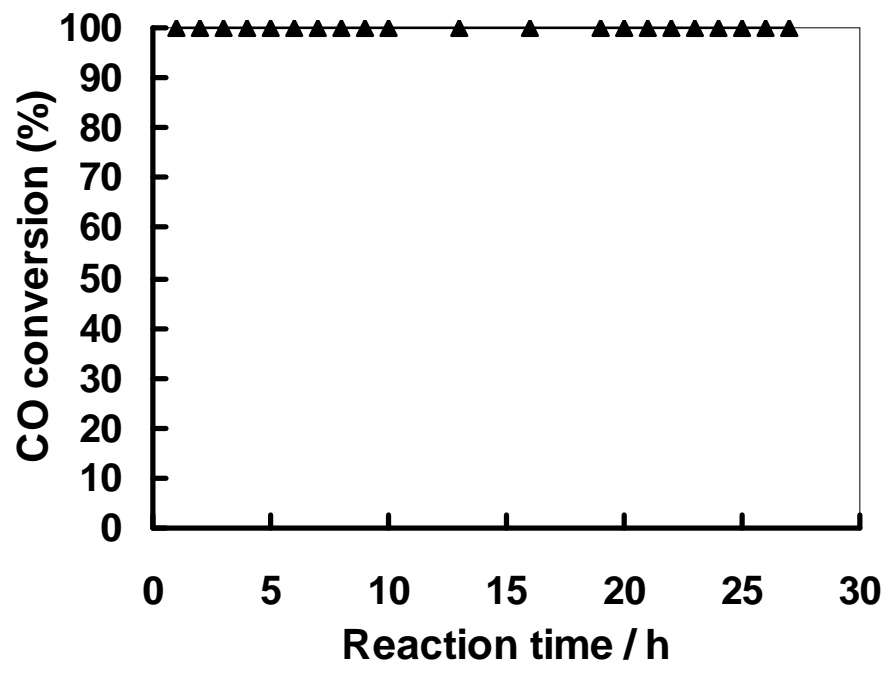

Fig. 7. PROX reaction by $0.5 \mathrm{wt} \% \mathrm{Pt} / \mathrm{FSM}-22(4.0)$ in the presence of water vapor and $\mathrm{CO}_{2}$. (a) Reaction conditions: catalyst $0.4 \mathrm{~g}, \mathrm{CO} 1 \mathrm{vol} \%, \mathrm{O}_{2} 1$ vol\%, $\mathrm{N}_{2} 5$ vol\%, $\mathrm{CO}_{2} 15$ vol $\%, \mathrm{H}_{2} \mathrm{O} 0.9$ vol $\%, \mathrm{H}_{2}$ balance, space velocity $3000 \mathrm{~mL} \mathrm{~g}^{-1} \mathrm{~h}^{-1}, 0.1 \mathrm{MPa}$; (b) Reaction conditions: catalyst $0.4 \mathrm{~g}, \mathrm{CO} 1$ vol $\%, \mathrm{O}_{2} 1$ vol $\%, \mathrm{~N}_{2} 5$ vol $\%, \mathrm{CO}_{2} 15$ vol $\%, \mathrm{H}_{2} \mathrm{O} 2$ vol $\%$, $\mathrm{H}_{2}$ balance, space velocity $3000 \mathrm{mLg}^{-1} \mathrm{~h}^{-1}, 0.1 \mathrm{MPa}$. 
Table 1 Structural parameters of supports and catalysts

\begin{tabular}{cccccc}
\hline Material & $S\left[\mathrm{~m}^{2} \mathrm{~g}^{-1}\right]^{a}$ & $D[\mathrm{~nm}]^{b}$ & $V\left[\mathrm{mLg}^{-1}\right]^{c}$ & $\mathrm{CO} / \mathrm{Pt}^{d}$ & $\mathrm{H} / \mathrm{Pt}^{d}$ \\
\hline FSM-10(1.8) & 1019 & 1.8 & 0.64 & - & \\
FSM-16(2.7) & 1028 & 2.7 & 1.16 & - & \\
FSM-22(4.0) & 1160 & 4.0 & 1.56 & - & \\
FSM-22(7.0) & 875 & 7.0 & 1.80 & - & \\
$\mathrm{Pt} / \mathrm{FSM}-10(1.8)^{e}$ & 985 & 1.8 & 0.66 & 0.39 & 0.30 \\
$\mathrm{Pt} / \mathrm{FSM}-16(2.7)^{e}$ & 988 & 2.7 & 1.17 & 0.24 & 0.27 \\
$\mathrm{Pt} / \mathrm{FSM}-22(4.0)^{e}$ & 1018 & 4.0 & 1.57 & 0.28 & - \\
$\mathrm{Pt} / \mathrm{FSM}-22(4.0)^{f}$ & 997 & 4.0 & 1.52 & 0.22 & 0.29 \\
$\mathrm{Pt} / \mathrm{FSM}-22(7.0)^{e}$ & 960 & 7.0 & 1.77 & 0.36 & 0.37 \\
$\mathrm{Pt} / \mathrm{SiO}_{2}{ }^{e}$ & 254 & - & & 0.19 & 0.16 \\
\hline
\end{tabular}

${ }^{a}$ BET (Brunauer-Emmet-Teller) surface area. ${ }^{b}$ Pore diameter by the BJH (BarrettJoyner-Halenda) method. ${ }^{c}$ Pore volume $\left(P / P_{0}=0.99\right) .{ }^{d}$ Uptake of $\mathrm{CO}$ or $\mathrm{H}_{2}$ on $\mathrm{Pt}$ surface in the pulse mode. ${ }^{e} \mathrm{Pt} 1 \mathrm{wt} \%{ }^{\circ} \mathrm{Pt} 0.5 \mathrm{wt} \%$. 


\title{
Preferential oxidation of carbon monoxide in excess hydrogen over platinum catalysts supported on different-pore-sized mesoporous silica
}

\author{
Shengjun Huang ${ }^{\text {a }}$, Kenji Hara ${ }^{\mathrm{a}}$, Yasuhiro Okubo ${ }^{\mathrm{b}}$, Masaaki Yanagi ${ }^{\mathrm{b}}$, Hironobu \\ Nanbu ${ }^{b}$, Atsushi Fukuoka ${ }^{\mathrm{a}, *}$ \\ ${ }^{a}$ Catalysis Research Center, Hokkaido University, Kita-21 Nishi-10, Kita-ku, Sapporo \\ 001-0021, Japan \\ ${ }^{\mathrm{b}}$ Taiyo Kagaku Co., Ltd., 1-3 Takaramachi, Yokkaichi, Japan.
}

Preferential oxidation of carbon monoxide has been studied over low loading of $\mathrm{Pt}$ catalysts supported on FSM-type mesoporous silica materials with different pore diameters. Despite the same Pt loading $(1 \mathrm{wt} \%)$ and similar specific surface areas $(\sim 1000$ $\left.\mathrm{m}^{2} \mathrm{~g}^{-1}\right)$, the catalysts exhibit different catalytic activities in the reaction. These results are informative for preparing lower Pt loading catalysts and for gaining more understanding of the catalytic role of mesoporous silica.

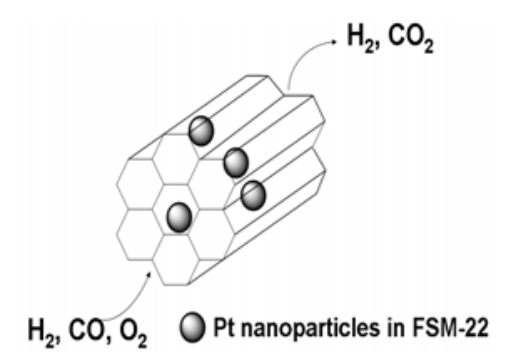

